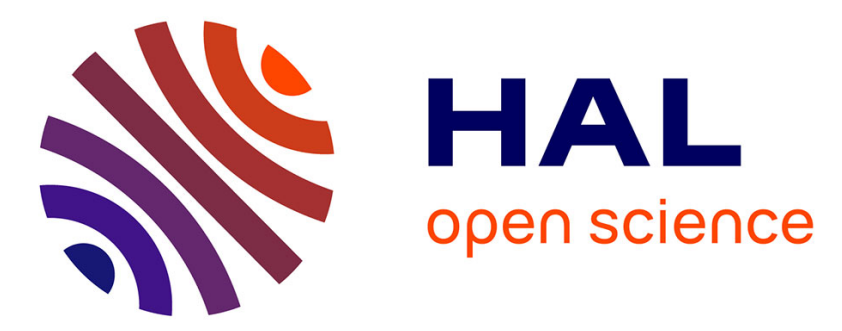

\title{
Assessment of movement patterns in Folsomia candida (Hexapoda: Collembola) in the presence of food
}

\author{
Apolline Auclerc, Paul-Antoine Libourel, Sandrine Salmon, Vincent Bels,
} Jean-François Ponge

\section{- To cite this version:}

Apolline Auclerc, Paul-Antoine Libourel, Sandrine Salmon, Vincent Bels, Jean-François Ponge. Assessment of movement patterns in Folsomia candida (Hexapoda: Collembola) in the presence of food. Soil Biology and Biochemistry, 2010, 42 (4), pp.657-659. 10.1016/j.soilbio.2009.12.012 . hal00493987

\section{HAL Id: hal-00493987 \\ https://hal.science/hal-00493987}

Submitted on 21 Jun 2010

HAL is a multi-disciplinary open access archive for the deposit and dissemination of scientific research documents, whether they are published or not. The documents may come from teaching and research institutions in France or abroad, or from public or private research centers.
L'archive ouverte pluridisciplinaire HAL, est destinée au dépôt et à la diffusion de documents scientifiques de niveau recherche, publiés ou non, émanant des établissements d'enseignement et de recherche français ou étrangers, des laboratoires publics ou privés. 
Type of contribution: Short communication

3 Date of preparation: 18 December 2009

4

5 Title: Assessment of movement patterns in Folsomia candida (Hexapoda: Collembola) in the presence

6 of food

7

8 Names of authors: A. Auclerc, P.A. Libourel, S. Salmon, V. Bels, J.F. Ponge*

9

10 Complete postal addresses or affiliations:

11

12 A. Auclerc, S. Salmon, J.F. Ponge: Muséum National d'Histoire Naturelle, CNRS UMR 7179, 4 avenue du Petit-Chateau, 91800 Brunoy, France

14

P.A. Libourel, V. Bels: Muséum National d'Histoire Naturelle, CNRS UMR 7179, 55 rue Buffon,

Case Postale 55, 75231 Paris Cedex 5, France

17

18 Full telephone, Fax number and E-mail address of the corresponding author:

19

20 Tel. +33678930133

$21 \quad$ Fax +33160465719

22 E-mail: ponge@mnhn.fr 


\section{Abstract}

We showed that Folsomia candida (a blind soil-dwelling Collembola) was able to shift from non-directional (random or search strategy) to directional (target-oriented) movements at short distance of food. We measured departure from linearity and access (or not) to food by the springtail according to distance to the target position. Video-records and image analysis were used to obtain numerical data at $0.2 \mathrm{sec}$ interval. The probability of food capture within $10 \mathrm{~min}$ (maximum duration of the experiment) was negatively related to distance. Two patterns can be observed along successful trajectories in our experimental conditions $\left(22^{\circ} \mathrm{C}\right.$, ambient light, still air), non-directional movement being followed by directional movement when the animals approach food at $25 \mathrm{~mm}$.

Keywords: Soil invertebrates; directional movement; food capture

\section{Text}

More has to be learned about the way soil invertebrates reach a target food or other favoured place without spending too much energy. While directional movements can be expected to waste less energy and time than random movements they need sophisticated sensory and nervous equipment (Applebaum and Heifetz, 1999). Between random and directional movements a third category consists of efficient 'search strategy', using looping behaviour (Bell, 1991). Bengtsson et al. (2004) and Wiktorsson et al. (2004) studied the small-scale movement of springtails in environments without food as attractant. Westerberg et al. (2008) showed that the presence of food decreased the time spent to move and modified looping behaviour. It was demonstrated that chemical cues are used by Collembola for attraction or avoidance, but experiments were made either by transporting odours via air currents in olfactometers (Hedlund et al., 1995) or using odour-conditioned places (Sadaka-Laulan et al., 1998; Nilsson and Bengtsson, 2004). It can be expected that (i) blind or eye-reduced soildwelling species will use rather odours as clues, contrary to aboveground species which use visual cues to move over long distances (Hågvar, 1995), and that (ii) this is possible only at short distance if 
only brownian motion (diffusion) transports olfactory molecules. Salmon and Ponge (2001) showed that the odour of earthworm excreta attracted the soil-dwelling Heteromurus nitidus at $1 \mathrm{~cm}$ distance, which is far below the range of higher insects (Laubertie et al., 2006). By studying the movement of animals deposited at varied distances from a food source we expect to find (i) a negative relationship between distance and success of food capture, and (ii) a shift from non-oriented (random or 'search strategy') to directional movements when food is perceived.

Folsomia candida Willem 1902 was used because of its insensitivity to light, which was verified beforehand: intolerance or attraction to light might interfere with the direction of movement (Salmon and Ponge, 1998). The trajectory was studied by video-tracking naive animals in short-time experiments $(<10 \mathrm{~min})$. Experiments were performed without soil in order to avoid any heterogeneity of the substrate and to follow individual animals continuously through an optical system. For that purpose the arena was made of a fine black cotton cloth which was thoroughly rinsed under tap water before each experimental run, thus avoiding pheromone deposition (Verhoef et al., 1977). The absence of air turbulence was provided by placing a glass cylinder $14 \mathrm{~cm}$ diameter and $30 \mathrm{~cm}$ height above the cotton cloth, which delimited the arena. The temperature was $22 \pm 1^{\circ} \mathrm{C}$ and the light was ambient light, to which $F$. candida was insensitive, as ascertained by preliminary experiments.

The animals were reared for several years on fine quartz sand moistened with tap water and were fed ad libitum with dried powdered cowdung. They also ate their excrements, which formed a thick layer covering the sand. This layer, made of an intimate mixture of cowdung debris and faeces, was used as attractant food in the experiments, Folsomia candida being pheromone-conditioned (Leonard and Bradbury, 1984). Animals (adults and sub-adults) were fed ad libitum until experiment. Food $(\sim 1 \mathrm{mg})$ was placed as a mound at the centre of the arena, 3-5 minutes before each experimental run, and was covered with a short piece of white cloth of similar area $\left(\sim 0.25 \mathrm{~cm}^{2}\right)$ for the need of image analysis. For each video-recorded run, one naive animal was introduced with a syringe at an uncontrolled distance from the side of the white cloth, varying from 1 to $50 \mathrm{~mm}$ (Fig. 1), and its movement was recorded with a Sony ${ }^{\circledR}$ DSR-PD100AP camera mounted on an adjustable support and 
connected to a personal computer, starting from the time the animal was deposited in the arena. On each run, which ended when food was encountered and movement ceased (the animal was no longer visible under the white cloth) or at $10 \mathrm{~min}$, white animals were followed on the black background by image analysis using Simulink ${ }^{\circledR}$ software. At each $0.2 \mathrm{sec}$ interval visual data were transformed into X and Y values for further calculations by Excel $^{\circledR}$ software. For the need of calculation, the path followed by the animal within each $0.2 \mathrm{sec}$ interval was assimilated to a straight line. By avoiding vibrations and shocks care was taken that no avoidance jump using the furcula occurred during the experiment. At each time of recording, the length of the trajectory followed by an animal from start was calculated by summing up $0.2 \mathrm{sec}$ segments. This allowed us to compare the distance remaining to travel to the distance in straight line to food. An efficiency index of movement (E.I.) was calculated by dividing the length of the trajectory by the straight line joining start and end of movement record.

The examination of the whole set of records (118) showed that about one third of animals (35) reached the food in the course of their wandering. Systematic search using looping behaviour, as described by Bengtsson et al. (2004), was not observed, although paths followed by animals could be crossed several times in the course of a single run. Successful food capture was negatively influenced by the distance at which the animals were placed at the start of the experiment, the rate of food capture decreasing from $65 \%$ at less than $1 \mathrm{~cm}$ to zero beyond $4 \mathrm{~cm}$ (Fig. 1). Logistic regression was performed with Addinsoft XLSTAT ${ }^{\circledR}$, using food capture $(0=$ failure, $1=$ success $)$ as dependent variable and distance to food at run start as independent variable. It showed that the probability of food capture (within $10 \mathrm{~min}$ ) was negatively influenced by the initial distance between the animal and the target food $(\mathrm{P}<0.0001)$. The efficiency of movement, as expressed by E.F., was 12.1 ( \pm 2.4 S.E.) in case of failure vs 4.5 ( \pm 0.8 S.E.) in case of success of food capture (Kolmogorov-Smirnov test, $\mathrm{P}<0.0001)$.

The trajectory followed by an animal was studied when it reached food within the maximum duration (10 $\mathrm{min}$ ) of the experiment (35 runs). The latter distance decreases in the course of the experiment, while the former increases or decreases according to the kind of behaviour of the animal. 
108 As an example, Figure 2 displays the characteristic patterns exhibited by an animal that reached food

109 in the course of the experiment. Two patterns can be distinguished, a first pattern corresponding to

110 wandering around the original position of the animal (random movement or 'search strategy'), and a

111 second pattern where and when the animal approaches food continuously. Although the second pattern

112 is represented by a straight line on Figure 2, the actual 2D-movement may be curvilinear (data not

113 shown). The straight distance to food below which the linear part was observed along the curve

114 measures the distance at which movement was directional. The average value was calculated to be

$11525.2 \mathrm{~mm}( \pm 1.4 \mathrm{~mm}$ S.E.). Given that the passage from the first to the second pattern of movement was

116 not exhibited at the same time for the whole set of animals tested, and because the rate of locomotion

117 strongly differed from an animal to another and within the same individual record, it was judged

118 impossible to incorporate time in a predictive model.

Within the limits of our study we confirm that olfactory signals are detected by soil 121 invertebrates over only a few centimetres, as already observed by Salmon and Ponge (2001) in $H$.

122 nitidus when attracted to earthworm odour. Here our method allows us to estimate it being $\sim 2.5 \mathrm{~cm}$ in F. candida, i.e. $1.5 \mathrm{~cm}$ longer than in earthworm-attracted $H$. nitidus. The examination of the whole set of successful trajectories (35) showed that the movement of an animal placed in the vicinity of a food source starts with non-directional movements (as exemplified by the zigzag part of the curve on Fig. 2) followed by directional movements (as exemplified by the final 'straight line' on Fig. 2). F. candida being insensitive to light, visual inspection of the environment can be discarded as an explanatory factor, but we cannot rule out that other factors than odour could contribute to reveal the presence of food, such as temperature gradients issuing from microbial respiratory metabolism.

\section{References} Review of Entomology 44, 317-41. 
Bell, W.J., 1991. Searching behaviour. Chapman and Hall, London.

138 Bengtsson, G., Nilsson, E., Ryden, T., Wiktorsson, M., 2004. Irregular walks and loops combines in small-scale movement of a soil insect: implications for dispersal biology. Journal of Theoretical Biology 231, 299-306.

Hågvar, S., 1995. Long distance, directional migration on snow in a forest Collembolan, Hypogastrura socialis (Uzel). Acta Zoologica Fennica 196, 200-205.

Hedlund, K., Bengtsson, G., Rundgren, S., 1995. Fungal odour discrimination in two sympatric species of fungivorous collembolans. Functional Ecology 9, 869-875.

Laubertie, E.A., Wratten, S.D., Sedcole, J.R., 2006. The role of odour and visual cues in the pan-trap catching of hoverflies (Diptera: Syrphidae). Annals of Applied Biology 148, 173-178.

Leonard, M.A., Bradbury, P.C., 1984. Aggregative behaviour in Folsomia candida (Collembola: Isotomidae), with respect to previous conditioning. Pedobiologia 26, 369-372.

Nilsson, E., Bengtsson, G., 2004. Death odour changes movement pattern of a Collembola. Oikos 104, 509-517. preferences of the Collembolan Onychiurus sinensis for fungi colonizing holm oak litter (Quercus rotundifolia Lam.). European Journal of Soil Biology 34, 179-188. Soil Biology 34, 199-201. 
164 Salmon, S., Ponge, J.F., 2001. Earthworm excreta attract soil springtails: laboratory experiments on

165

166

167

168

169

170

171

172

173

174 Wiktorsson, M., Rydén, T., Nilsson, E., Bengtsson, G., 2004. Modelling the movement of a soil insect. Heteromurus nitidus (Collembola: Entomobryidae). Soil Biology and Biochemistry 33, 19591969.

Verhoef, H.A., Nagelkerke, C.J., Joosse, E.N.G., 1977. Aggregation pheromones in Collembola. Journal of Insect Physiology 23, 1009-1013.

Westerberg, L., Lindström, T., Nilsson, E., Wennergren, U., 2008. The effect on dispersal from complex correlations in small-scale movement. Ecological Modelling 213, 263-272. Journal of Theoretical Biology 231, 497-513.

176 


\section{Figure captions}

178

179 Figure 1. The influence of distance to food at run start (abscissa) on the probability of food capture within experimental time (ordinate). Distances were classified in five groups $(\mathrm{n}=$ number of runs)

182

183 Figure 2. Graphical representation of the distance remaining to travel along a given trajectory according to straight distance to food (an individual run is shown here as example). The zigzag part of the curve (non-directional movement) is followed by a linear part (directional movement) 


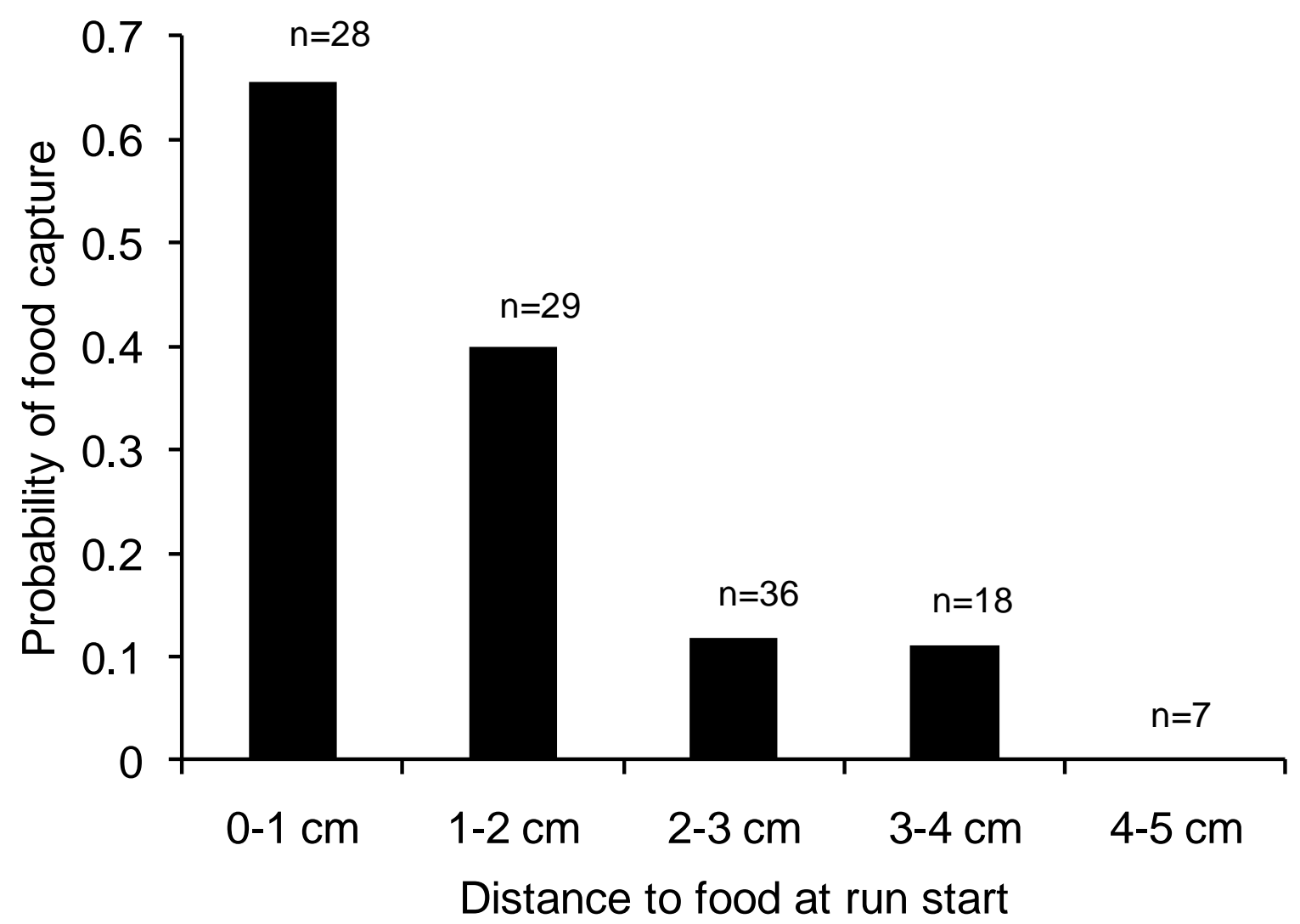

188

$190 \quad$ Fig. 1 


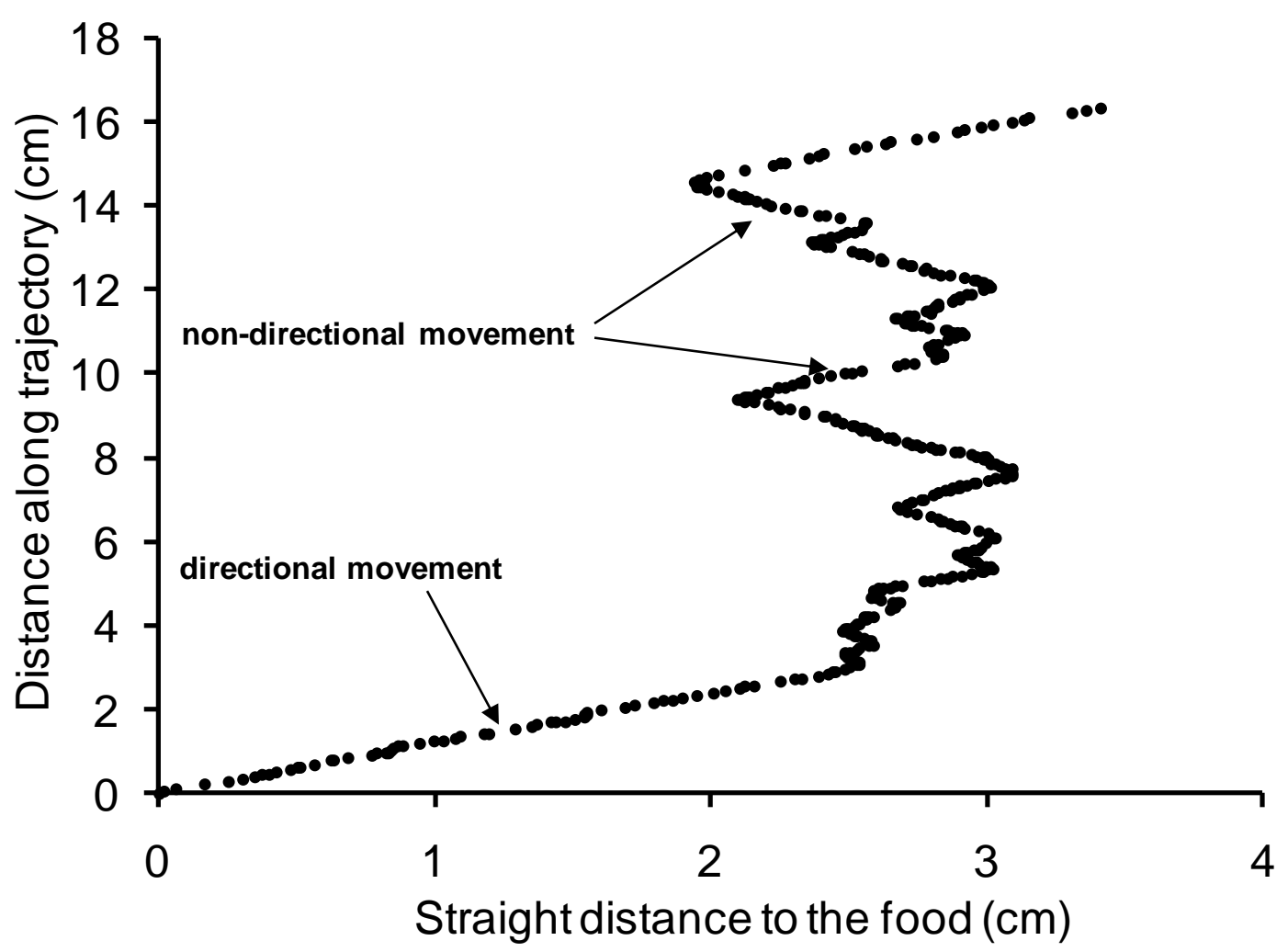

192

193

$194 \quad$ Fig. 2 